\title{
Seismic hazard reassessment of an existing NPP in Slovenia
}

\author{
Lapajne, J.K. ', Fajfar, P. ${ }^{2}$ \\ 1) Ministry of the Environment and Regional Planning, Geophysical Survey of Slovenia, Ljubljana, \\ Slovenia \\ 2) University of Ljubljana, Ljubljana, Slovenia
}

\begin{abstract}
A seismic hazard reassessment of the site of an existing nuclear power plant in Slovenia was performed. The study was based on existing data only. To overcome the lack of data and to handle uncertainties in the data, a multiple model approach was implied. Tectonic interpretations, seismic source determinations and estimates of the uncertainty were made by three independent earth-scientists' groups. The results of the study are in the form of seismic hazard curves and spectra.
\end{abstract}

\section{INTRODUCTION}

The seismic design of the Krško nuclear power plant (NPPK) in Slovenia was performed using the contemporary state of the art in the early 70s. Two types of design ground motion were evaluated: "operating basis earthquake" and "safe-shutdown earthquake". Peak ground acceleration was applied as a ground motion parameter, and the NRC RG 1.60 spectrum was used

A reassessment of the seismic hazard at the site of NPPK was initiated in 1992 (Institute of Structural and Earthquake Engineering, 1994). Due to the limitation imposed by time, funds and human resources, the study is based on existing data only. A lack of seismological, particularly strong motion data and geological data was the main problem. There was little agreement among geologists on the existence and seismic activity of faults. To overcome the lack of data and to handle uncertainties in the data, different seismotectonic models and seismic source models were developed by three independent earth-scientists' groups. Probabilistic seismic hazard analysis (PSHA), based on an expansion of the basic approach by Cornell (1968), was applied. The computer program FRISK 88 (Risk Engineering, 1988) was used for the calculation of seismic hazard curves.

PSHA consists of the preparation of the earthquake catalogue, the seismotectonic study, the determination of seismic sources and their parameters, the determination of ground motion attenuation models, the calculation of seismic hazard curves for peak ground acceleration (PGV) and pseudo spectral velocity (PSV), and the calculation of uniform hazard spectra for PSV and pseudo spectral acceleration (PSA). A deterministic hazard assessment has also been performed in order to compare the results.

Two scales have been adopted for specifying seismic sources. The two scales correspond to the regional and near regional scale as defined by the International Atomic Energy Agency (1991). The regional study covers a geographical area of radius $150 \mathrm{~km}$, more in some directions. The near regional study covers a geographical area of 3,000 to $4,000 \mathrm{~km}^{2}$. This area, which was studied in greater detail, is elongated in the direction 
SW-NE. The applied multiple model PSHA is roughly similar to that used for seismic hazard estimation at 69 nuclear plant sites in central and eastern parts of the United States (Electric Power Research Institute, 1988, Bernreuter et al., 1989).

\section{SEISMIC SOURCES}

Seismotectonic study consists mainly of the identification of potentially active tectonic features. Active tectonic features and locations of past earthquakes identify probable future earthquake or seismic sources. Seismotectonic studies were performed independently by three earth-scientists' groups. The existing geological, seismological, geophysical, and geotechnical database was available to all of them. Assessment of the relevance of data, the consideration given to the individual data within the chosen method of interpretation, and time and money restraints, were at the discretion of the individual group.

The same earthquake catalogue was used by all three groups. The catalogue was formed by merging the catalogue of Slovenia and the catalogues of border regions in the neighbouring countries: Italy, Austria, Hungary and Croatia. The catalogue covers the period 567-1990 A.D. and an area of approximately $70,000 \mathrm{~km}^{2}$.

The fairly high uncertainty of earthquake and fault locations did not allow the assignment of seismic events to faults. Thus, earthquakes were modelled mainly as random seismicity within area sources capable of producing earthquakes equal to or greater than a chosen lower-bound magnitude. Area sources were defined as polygons in the horizontal plane with fixed depth. Lower-bound magnitude was set for all seismic sources at 5.0 based on consensus in the engineering community that an earthquake of magnitude less than 5.0 does not produce effects of engineering interest. In addition to area sources in the near region, some faults capable of generating earthquakes of magnitude about 6.0 or more were modelled as fault sources. Average slip rates were roughly estimated for these faults. Fault sources were defined as vertical or dipping planes between the minimum and maximum depths of energy release. The three groups defined quite different geometries of seismic sources. Since all groups used the same earthquake catalogue, it is obvious that this was mainly caused by different interpretations of geology and tectonics.

Estimates of upper-bound magnitude were based either on the earthquake catalogue or on assumed fault rupture dimensions. The cumulative annual number of earthquakes exceeding the chosen lower-bound magnitude (activity rate) of area sources was calculated using the complete parts of the earthquake catalogue. The activity rate of fault sources was evaluated from roughly assessed average fault slip rates (Youngs \& Coppersmith, 1985). The decay rate of the magnitude recurrence was estimated by a normalised doubly-truncated Gutenberg - Richter exponential magnitude recurrence relationship (Youngs \& Coppersmith, 1985). For the defined fault sources, no data for either surface or subsurface rupture sizes exists, so published relevant relationships between rupture size and magnitude (Bonilla et al, 1984; Wells \& Coppersmith, 1994) were applied. The lower and upper values of seismic source parameters were constrained by different, more or less subjective criteria (e.g., Lapajne et al., 1994).

\section{ATTENUATION MODELS}

The same attenuation model was applied to all seismic source models. The choice of the attenuation model has proven to be the most important factor of seismic hazard at the site. Unfortunately, only a very small number of strong motion accelerograms have been recorded in the investigated area, and no attenuation model has been developed for these 
regions so far. For this reason, it was decided to use the model proposed by the Italian authors Pugliese and Sabetta, (1989). The Sabetta-Pugliese (SP) model is based on earthquakes, similar to those affecting the NPPK site. The model was developed by statistical analysis of ground motions recorded in Italy. Almost half of the records apply to earthquakes in Friuli, which has an overall geology similar to the geology of the investigated area. The distance of NPPK from Friuli is only about $200 \mathrm{~km}$. In addition, the SP attenuation model gives equations dependent on local soil conditions for all relevant parameters (PGA, PGV, and PSV for 5 percent damping). The category "deep soil deposits" was chosen to approximate the actual local soil conditions in the near region. One drawback of the SP model is its uncertainty at small distances from the energy release, as the model does not explicitly take into account the depth of the energy release.

In addition to the SP model, a recent attenuation model developed by Campbell and Borzorgnia (1994) was used (CB model). This model applies to near-source locations and explicitly takes into account the depth of the energy release. A depth of $3.5 \mathrm{~km}$ from the top of the seismogenic rupture was assumed. Unfortunately, only the attenuation relation for PGV is available. There is no consensus among different earth-science teams on the type of faulting, so, an average of strike-slip and reverse faulting was used. The local site geology was defined as "alluvium". In the study, PGAs were determined by both models, with weighting of 0.7 and 0.3 attached to the SP and CB models, respectively. The rest of the spectrum was determined by the SP model only.

\section{SEISMIC HAZARD IN THE FREE FIELD}

Calculation of the probabilistic seismic hazard in the free field was performed in three stages. Sensitivity analysis of the three seismic source models was the first stage. After consideration of the results of this analysis, some simplifications of the models were made. The second stage was a screening procedure, the purpose of which was to eliminate seismic sources with negligible contribution to hazard at the site. It was found that near region seismic sources contributed more than $98 \%$ of the total seismic hazard defined either for PGA at $0.3 \mathrm{~g}$ or for PSV at $1 \mathrm{~s}$ and return period of 1000 years. Therefore, all regional seismic sources were eliminated from further consideration. In the final stage, 15th, 50th, and 85th percentile hazard curves, and uniform hazard spectra for 1000,5000 , and 10000 years were calculated. Hazard curves and spectra were calculated for each of the three models, and for all models together assigning equal weighting to them. Results are given in Figure 1 and Figure 2.

\section{LOCAL EARTHQUAKES}

The accelerograph SMA-1, installed in the free field about $50 \mathrm{~m}$ from the main buildings of the NPPK recorded 6 small magnitude local earthquakes with rather high PGAs in the period 1981-89. The highest recorded horizontal PGA was more than $0.4 \mathrm{~g}$ (the magnitude was only 3.9). Weighted mean and weighted mean plus sigma value for the six spectra normalised to PGA are shown in Figure 3. The weights are proportional to PGAs. A relatively small standard deviation can be observed. High frequencies (low periods) are clearly predominant. A sharp peak occurs in the period range 0.08 to 0.09 seconds (frequencies $11-12 \mathrm{~Hz}$ ). The spectral values decrease rapidly with an increase of the period. A very short duration of strong ground motion (less than 1 second) was observed in all records. The input energy of such ground motion is extremely small. According to experience, such ground motions do not damage buildings and equipment, 

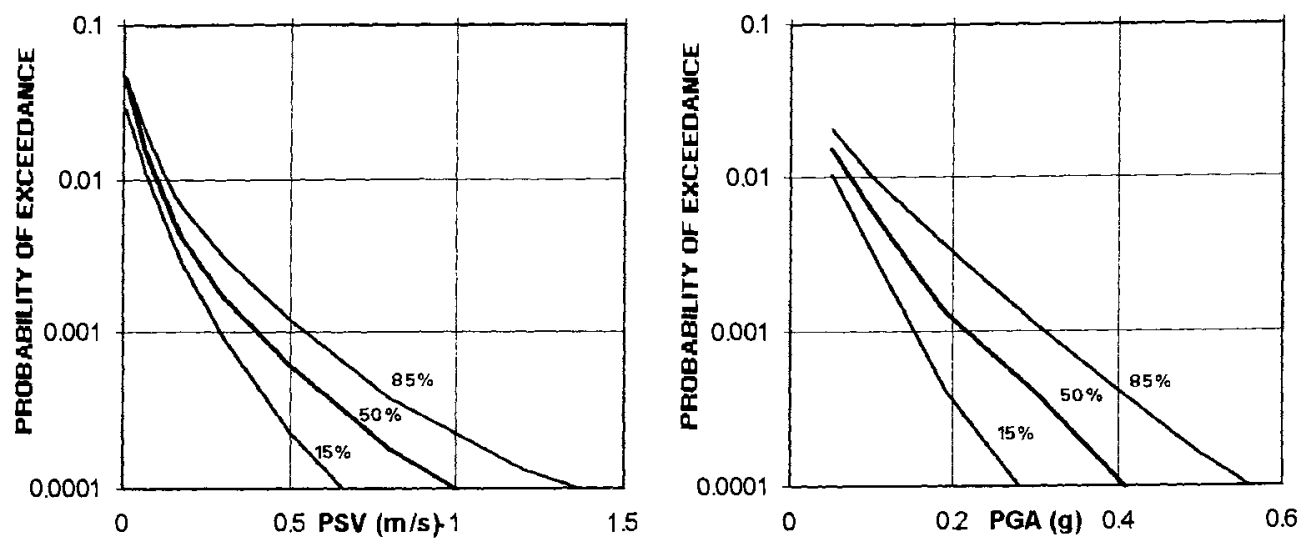

Figure 1. Percentile hazard curves for PSV (for $T=1 \mathrm{~s}$ ) and PGA.
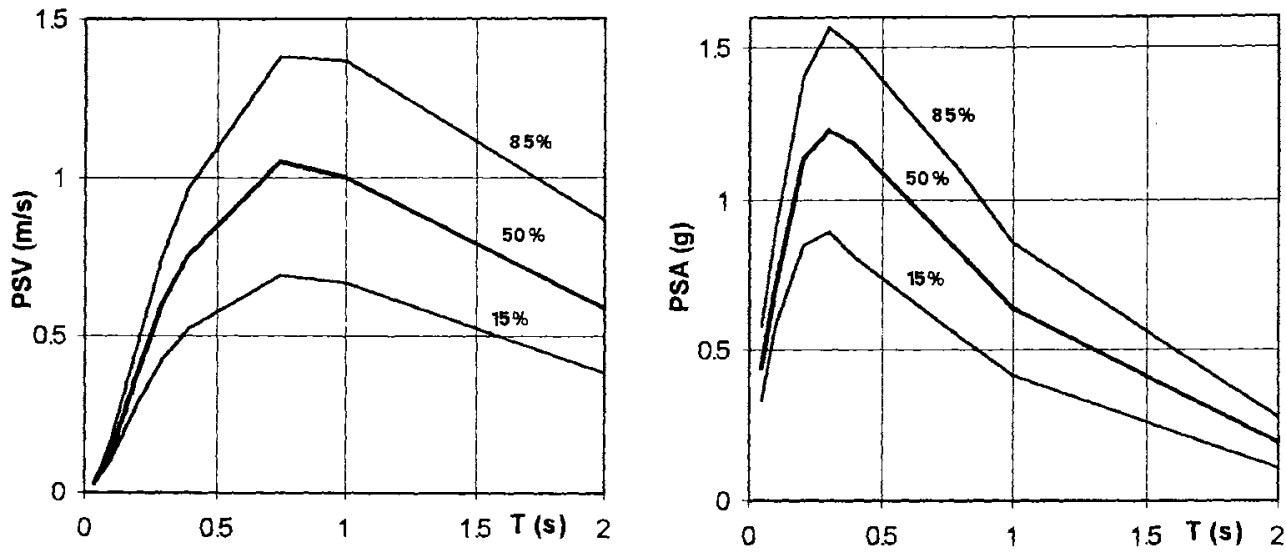

Figure 2. Uniform hazard spectra for PSV (for earthquake return period 10,000 years) and PGA.

with the possible exception of some high frequency components, for example relay chatter. Accelerograms obtained at the foundations of buildings were systematically much smaller than the appurtenant free field accelerograms.

Acceleration spectra, traditionally used for structure design, do not provide any information on the duration of ground motion and do not take this parameter into account, which is of great importance for input energy. For this, reason we believe that it is not correct to treat weak local earthquakes with short duration and predominantly high periods in seismic hazard analysis in the same way as ground motions with "standard" characteristics. We propose two different types of ground motion in further studies of seismic safety of buildings and equipment in the NPPK. The characteristics of the first type are defined by spectra obtained by PSHA in the study. The second type corresponds to small local earthquakes and is defined by the idealised spectrum given in Figure 3 and strong motion duration of up to 1 second.

\section{DETERMINISTIC SEISMIC HAZARD ANALYSIS}

A number of independent deterministic analyses were carried out in order to check the results obtained by the probabilistic analysis. The first was based on selected seismic 


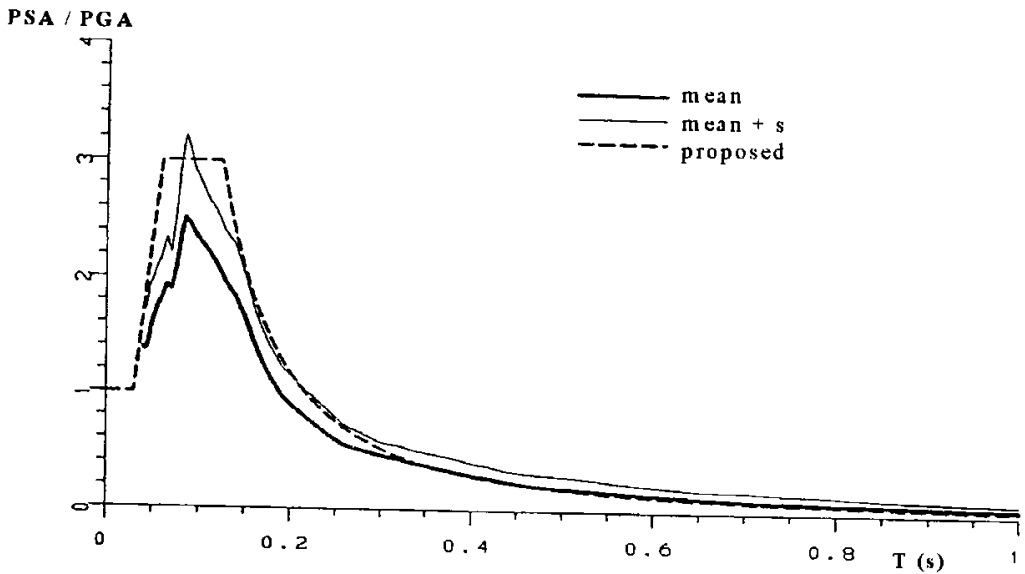

Figure 3. Weighted mean acceleration spectra corresponding to records obtained at the NPPK site and proposed design spectrum for local earthquakes.
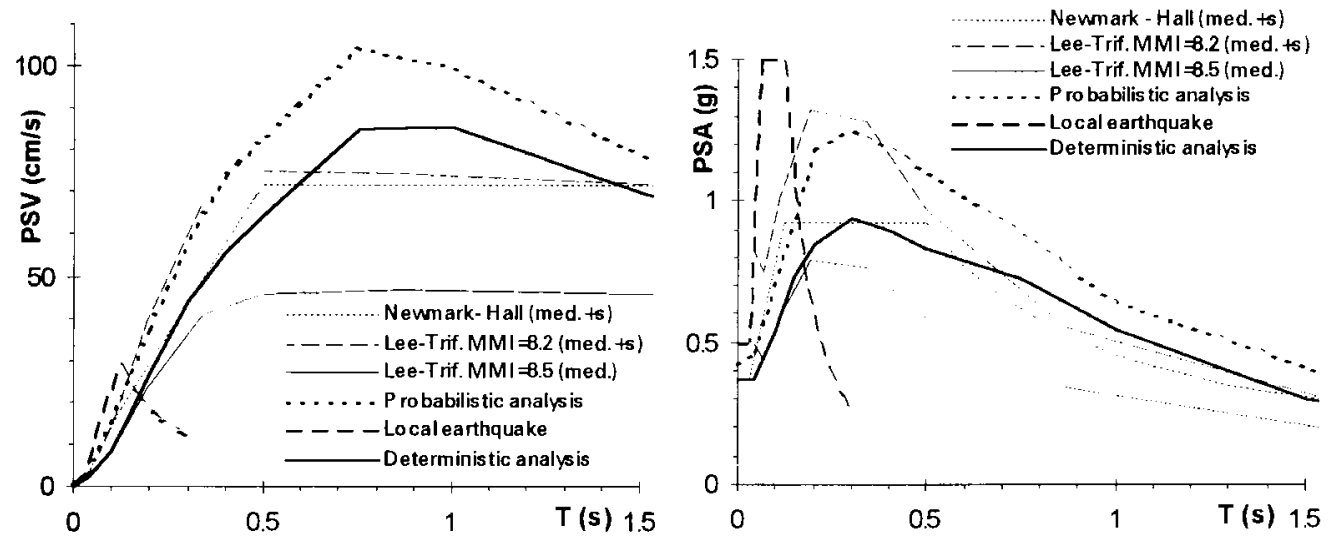

Figure 4. Velocity and acceleration spectra obtained according to different procedures.

sources and corresponding seismic parameters determined by three independent earthscientist's groups and the attenuation models used in the study. In the second, the analysis spectra of the Newmark-Hall (1982) type were computed. The data for PGA and PSV determined within the first analysis were used in the procedure, and multiplied by amplification factors as determined in a recent study by Vidic et al (1994). Within the third analysis, the maximum expected intensity at the NPPK site was estimated at 9 according to MCS and MSK scales. This intensity corresponds to MMI intensities 8.2 and 8.5 (Trifunac, 1977; Trifunac and Živčić, 1991). The corresponding spectra were computed according to the procedure developed by Lee and Trifunac (Lee, 1991). The results of the three analyses are shown in Figure 4, compared to the median spectrum obtained in the probabilistic analysis for the return period of 10000 years.

\section{CONCLUSION}

We hope that the multiple model approach has adequately taken into account the uncertainties in the data, and that the resulting hazard curves and uniform hazard spectra are a reasonable input for the probabilistic risk assessment of the plant. The study has 
shown that, although the seismotectonic models of the three earth-scientists' groups were rather different, they did not result in essentially different cumulative hazard curves and spectra.

\section{REFERENCES}

Bernreuter, D.L., J.B. Savy, R.W. Mensing \& J.C. Chen 1989. Seismic Hazard Characterisation of 69 Nuclear Plant Sites East of the Rocky Mountains, NUREG/CR-5250, UCID-21517, Lawrence Livermore National Laboratory, Livermore.

Bonilla, M.G., R.K. Mark \& J.J. Lienkaemper 1984. Statistical relations among earthquake magnitude, surface rupture length, and surface fault displacement, Bull. Seism. Soc. Am. 74, 2379-2411.

Campbell, K. W. \& Y. Bozorgnia 1994. Near-source attenuation of peak horizontal acceleration from worldwide accelerograms recorded from 1957 to 1993, Proc. 5th U.S. National Comf. Earthquake Eng., Chicago, Vol. 3, 283-292.

Cornell, C.A. 1968. Engineering Seismic Risk Analysis, Bull. Seism. Soc. Am. 58, 1583-1606.

Electric Power Research Institute 1988. Seismic Hazard Methodology for the Central and Eastern United States, Revision I, Final Report, EPRI NP-4726-A, Palo Alto.

Institute of Structural and Earthquake Engineering 1994. Probabilistic assessmem of seismic hazard at Krško Nuclear Power Plant, Revision 1, Final Report, University of Ljubljana, Department of Civil Engineering, Ljubljana.

International Atomic Energy Agency 1991. Earthquake and Associated Topics in Relation to Nuclear Power Plant Siting, Safety Guides within The NUISS Programme, Safety Series No. 50-SG-S1 Rev. 1, IAEA, Vienna.

Lapajne, J. K., E. Prelogović, B. Šket Motnikar \& P. Zupančič 1994. Constraints in the estimation of seismic source parameters for Krško NPP site in Slovenia, 9th International Seminar on Earthqmake Prognostics, San José, Costa Rica.

V. W, A. Lee, 1991. Correlation of pseudo relative velocity spectra with site intensity, local soil classification and depth of sediments, Soil Dynamics Earthquake Eng. 10, 141-151.

Newmark, N. M. \& W. J. Hall 1982. Earthquake spectra and design, EERI, Berkeley.

Pugliese, A. \& F. Sabetta 1989. Stima di spettri di risposta da registrazioni di forti terremoti italiani, Ingegneria Sismica VI/2, 3-14.

Risk Engineering 1988. FRISK88 User's Mamual, Version 1.2, Risk Engineering, Golden, Colorado.

Trifunac, M. D. 1977. An instrumental comparison of the Modified Mercalli (MMI) and Medvedev-Karnik-Sponheuer (MKS) intensity scales, Proc. 6th World Conf. Earthquake Eng., New Delhi, India, 2-359.

Trifunac, M. D. \& M. Živčić 1991. A note on instrumental comparison of the Modified Mercalli Intensity (MMI) in the western United States and the Mercalli-CancaniSieberg (MCS) intensity in Yugoslavia, European Earthquake Eng. 5, 22-26.

Vidic, T., P. Fajfar \& M. Fischinher 1994. Consistent inelastic design spectra: strength and displacement, Earthquake Eng. Struct. Dyn. 23, 507-521.

Wells, D.L. \& K.J. Coppersmith 1994. New empirical relationships among magnitude, rupture length, rupture with, rupture area, and surface displacement, Bull. Seism. Soc. Am. 84, 974-1002

Youngs, R.R. \& K.J. Coppersmith 1985. Implication of Fault Slip Rates and Earthquake Recurrence Models to Probabilistic Seismic Hazard Estimates, Bull. Seism. Soc. Am. 75, 939-964. 